\title{
Two Cooperating Manipulators with Fractional Controllers
}

\author{
N. M. Fonseca Ferreira \\ Department of Electrical Engineering, Institute of Engineering of Coimbra \\ Rua Pedro Nunes, 3031-601 Coimbra, Portugal \\ nunomig@isec.pt \\ J. A. Tenreiro Machado \\ Department of Electrical Engineering, Institute of Engineering of Porto \\ Rua Dr. António Bernardino de Almeida, 4200-072 Porto, Portugal \\ jtm@isep.ipp.pt \\ József K. Tar \\ Budapest Tech, John von Neumann, Faculty of Informatics \\ Inst. of Intelligent Engineering Systems \\ Bécsiút 96/B, H-1034, Budapest, Hungary \\ tar.jozsef@nik.bmf.hu
}

\begin{abstract}
This paper analyzes the dynamic performance of two cooperative robot manipulators. It is studied the implementation of fractional-order algorithms in the position/force control of two cooperating robotic manipulators holding an object. The simulations reveal that fractional algorithms lead to performances superior to classical integer-order controllers.
\end{abstract}

\section{Introduction}

Two robots carrying a common object are a logical alternative for the case in which a single robot is not able to handle the load. The choice of a robotic mechanism depends on the task or the type of work to be performed and, consequently, is determined by the position of the robots and by their dimensions and structure. In general, the selection is done through experience and intuition; nevertheless, it is important to measure the manipulation capability of the robotic system (Y. C. Tsai \& A.H Soni., 1981) that can be useful in the robot operation. In this perspective it was proposed the concept of kinematic manipulability measure (T. Yoshikawa, 1985) and its generalization to dynamical manipulability (H. Asada, 1983) or, alternatively, the statistical evaluation of manipulation (J. A. Tenreiro. Machado \& A. M. Galhano, 1997). Other related aspects such as the coordination of two robots handling 
objects, collision avoidance and free path planning have been also investigated (Y. Nakamura, K. Nagai, T. Yoshikawa, 1989) but they still require further study.

With two cooperative robots the resulting interaction forces have to be accommodated and consequently, in addition to position feedback, force control is also required to accomplish adequate performances (T. J. Tarn, A. K. Bejczy, P. K., 1996) and (N. M. Fonseca Ferreira, J. A. Tenreiro Machado, 2000) and (A. K. Bejczy and T. Jonhg Tarn, 2000). There are two basic methods for force control, namely the hybrid position/force and the impedance schemes. The first method (M. H. Raibert and J. J. Craig, 1981) separates the task into two orthogonal sub-spaces corresponding to the force and the position controlled variables. Once established the subspace decomposition two independent controllers are designed. The second method (N. Hogan, 1985) requires the definition of the arm mechanical impedance. The impedance accommodates the interaction forces that can be controlled to obtain an adequate response. Others authors (Kumar, Manish; Garg, Devendra 2005, Ahin Yildirim, 2005, Jufeng Peng, Srinivas Akella, 2005) present advance methodologies to optimize the control of two cooperating robots using the neural network architecture and learning mechanism to train this architecture online. This paper analyzes the manipulation and the payload capability of two arm systems and we study the position/force control of two cooperative manipulators, using fractional-order $(F O)$ algorithms (J. A. Tenreiro Machado, 1997) and (N. M. Fonseca Ferreira \& J. A. Tenreiro Machado 2003, 2004 and 2005).

Bearing these facts in mind this article is organized as follows. Section two presents the controller architecture for the position/force control of two robotic arms. Based on these concepts, section three develops several simulations for the statistical analysis and the performance evaluation of FO and classical PID controllers, for robots having several types of dynamic phenomena at the joints. Finally, section four outlines the main conclusions.

\section{Control of Two Arms}

The dynamics of a robot with $\mathrm{n}$ links interacting with the environment is modelled as:

$$
\tau=\mathbf{H}(\mathbf{q}) \ddot{\mathbf{q}}+\mathbf{C}(\mathbf{q}, \dot{\mathbf{q}})+\mathbf{G}(\mathbf{q})-\mathbf{J}^{\mathbf{T}}(\mathbf{q}) \mathbf{F}
$$

where $\tau$ is the $n \times 1$ vector of actuator torques, $\mathbf{q}$ is the $n \times 1$ vector of joint coordinates, $\mathbf{H}(\mathbf{q})$ is the $n \times n$ inertia matrix, $\mathbf{C}(\mathbf{q}, \dot{\mathbf{q}})$ is the $n \times 1$ vector of centrifugal/Coriolis terms and $\mathbf{G}(\mathbf{q})$ is the $n \times 1$ vector of gravitational effects. The $n \times m$ matrix $\mathbf{J}^{\mathbf{T}}(\mathbf{q})$ is the transpose of the Jacobian of the robot and $\mathbf{F}$ is the $m \times 1$ vector of the force that the (m-dimensional) environment exerts in the gripper.

We consider two robots with identical dimensions (Fig. 1). The contact of the robot gripper with the load is modelled through a linear system with a mass $M$, a damping $B$ and a stiffness $K$ (Fig. 2). The numerical values adopted for the $R R$ (where $R$ denote rotational joints) robots and the object are $m_{1}=m_{2}=1.0 \mathrm{~kg}, l_{1}=l_{2}=l_{\mathrm{b}}=l_{0}=1.0 \mathrm{~m}, \alpha_{0}=0 \mathrm{deg}, B_{1}=B_{2}=$ $1 \mathrm{Nsm}^{-1}$ and $K_{1}=K_{2}=10^{4} \mathrm{Nm}^{-1}$. 


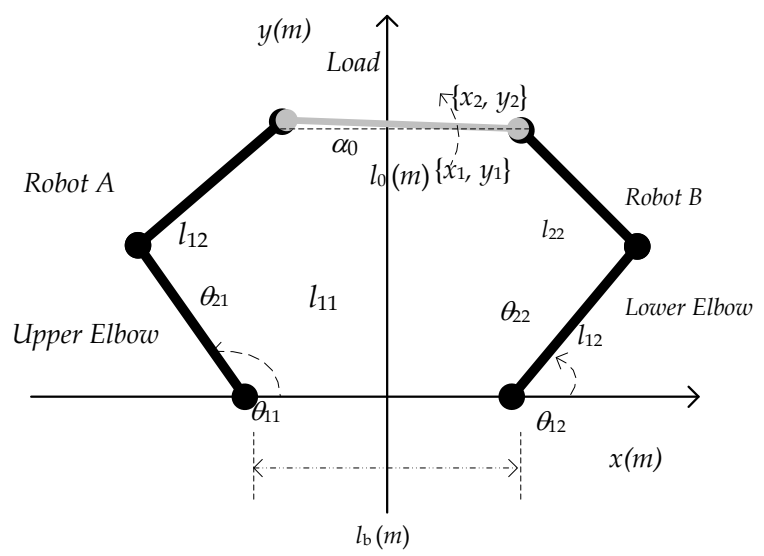

Fig. 1. Two $R R$ robots working cooperation for the manipulation of an object with length $l_{0}$ and orientation $\alpha_{0}$.

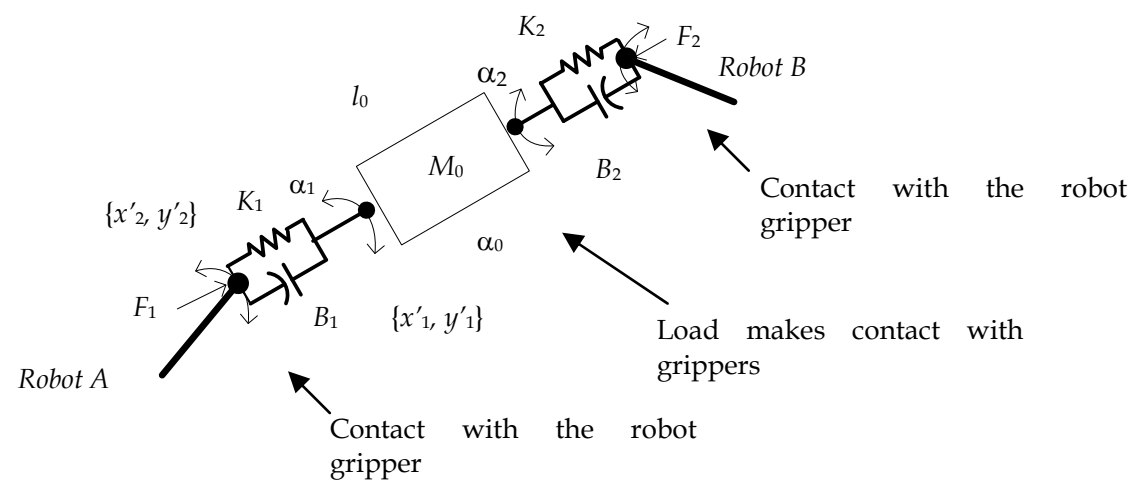

Fig. 2. The contact between the robot gripper and the object.

The controller architecture (Fig. 3), is inspired on the impedance and compliance schemes. Therefore, we establish a cascade of force and position algorithms as internal an external feedback loops, respectively, where $x_{d}$ and $F_{d}$ are the payload desired position coordinates and contact forces. 


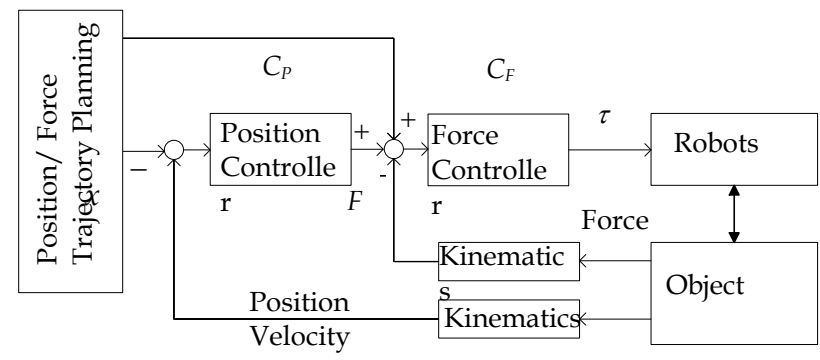

Fig. 3. The position/force cascade controller.

In the position and force control loops we consider FO controllers of the type $C(s)=K_{\mathrm{p}}+$ $K_{\alpha} s^{\alpha},-1<\alpha<1$, that are approximated by $4^{\text {th }}$ order discrete-time Pade expressions $\left(a_{\mathrm{i}}, b_{\mathrm{i}}, \mathfrak{R}\right.$, $k=4)$ :

$$
C(z) \approx K_{p}+K_{\alpha} \frac{\sum_{k=0}^{4} a_{k} z^{4-k}}{\sum_{k=0}^{4} b_{k} z^{4-k}}
$$

We compare the response with the classical PD-PI algorithms therefore, in the position and force loops we consider, respectively.

$$
\begin{gathered}
C(s)=K_{p}+K_{d} s \\
C(z)=K_{p}+K_{d}\left(1-z^{-1}\right) \\
C(s)=K_{p}+K_{i} \frac{1}{s} \\
C(z)=K_{p}+K_{i} \frac{z}{z-1}
\end{gathered}
$$

Both algorithms were tuned by trial and error, having in mind getting a similar performance in the two cases (Tables 1 and 2).

\begin{tabular}{lllllll}
\hline$i$ & $K_{\mathrm{p}}$ & $K_{\alpha}$ & $\alpha$ & $K_{\mathrm{p}}$ & $K_{\alpha}$ & $\alpha$ \\
\hline 1 & 0.1259 & $1.55510^{-3}$ & $\frac{1}{2}$ & 10.59 & $2.010^{-3}$ & $-\frac{1}{5}$ \\
2 & 0.1259 & $1.55510^{-3}$ & $\frac{1}{2}$ & 10.59 & $2.010^{-3}$ & $-\frac{1}{5}$ \\
\hline
\end{tabular}
(a) Position controller
(b) Force controller

Table 1. The parameters of the position and force FO controllers. 


\begin{tabular}{lllll}
\hline $\boldsymbol{i}$ & $\boldsymbol{K}_{\mathbf{p}}$ & $\boldsymbol{K}_{\mathbf{d}}$ & $\boldsymbol{K}_{\mathbf{p}}$ & $\boldsymbol{K}_{\boldsymbol{i}}$ \\
\hline 1 & $25010^{2}$ & $2.510^{1}$ & $5.010^{1}$ & $10.010^{1}$ \\
2 & $25010^{2}$ & $2.510^{1}$ & $5.010^{1}$ & $10.010^{1}$ \\
\hline
\end{tabular}

$\begin{array}{ll}\text { (a) Position controller } & \text { (b) Force controller }\end{array}$

Table 2. The parameters of the position and force PD-PI controllers.

\section{Analysis of the system performance}

In order to study the system dynamics we apply a small amplitude rectangular pulse $\delta y_{d}$ at the position reference and we analyze the system response.

The simulations adopt a controller sampling frequency $f_{\mathrm{c}}=10 \mathrm{kHz}$, contact forces of the grippers $\left\{F x_{j}, F y_{j}\right\} \equiv\{0.5,5\} \mathrm{Nm}$, a operating point of the center of the object $\mathrm{A} \equiv\{x, y\} \equiv\{0,1\}$ and a load orientation of $\alpha=0^{\circ}$.

In a first phase we consider robots with ideal transmissions at the joints. Figure 4 depicts the time response of robot $\mathrm{A}$ under the action of the FO and PD-PI algorithms.

In a second phase (figure 5) we analyze the response of robots with dynamic backlash at the joints. For the $i_{\text {th }}$ joint $(i=1,2)$, with gear clearance $h_{\mathrm{j}}$, the backlash reveals impact phenomena between the inertias, which obey the principle of conservation of momentum and the Newton law:

$$
\begin{gathered}
\dot{q}_{i}^{\prime}=\frac{\dot{q}_{i}\left(J_{i i}-\varepsilon J_{i m}\right)+\dot{q}_{i m} J_{i m}(1+\varepsilon)}{J_{i i}+J_{i m}} \\
\dot{q}_{i m}^{\prime}=\frac{\dot{q}_{i} J_{i}(1+\varepsilon)+\dot{q}_{i m}\left(J_{i m}-\varepsilon J_{i i}\right)}{J_{i i}+J_{i m}}
\end{gathered}
$$

where $0 \leq \varepsilon \leq 1$ is a constant that defines the type of impact $(\varepsilon=0$ inelastic impact, $\varepsilon=1$ elastic impact) and $\dot{q}_{i}$ and $\dot{q}_{i m}\left(\dot{q}_{i}^{\prime}\right.$ and $\left.\dot{q}_{i m}^{\prime}\right)$ are the velocities of the $i$ th joint and motor before (after) the collision, respectively. The parameter $J_{i i}\left(J_{i m}\right)$ stands for the link (motor) inertias of joint $i$. The numerical values adopted are $h_{\mathrm{i}}=1.810^{-4} \mathrm{rad}$ and $\varepsilon_{\mathrm{i}}=0.8(i=1,2)$.

In a third phase (figure 6) we study the $R R$ robot with compliant joints. For this case the dynamic model corresponds to model (1) augmented by the equations:

$$
\begin{gathered}
\tau=\mathbf{J}_{\mathrm{m}} \ddot{\mathbf{q}}_{\mathrm{m}}+\mathbf{B}_{\mathrm{m}} \dot{\mathbf{q}}_{\mathrm{m}}+\mathbf{K}_{\mathrm{m}}\left(\mathbf{q}_{\mathrm{m}}-\mathbf{q}\right) \\
\mathbf{K}_{\mathrm{m}}\left(\mathbf{q}_{\mathrm{m}}-\mathbf{q}\right)=\mathbf{J}(\mathbf{q}) \ddot{\mathbf{q}}+\mathbf{C}(\mathbf{q}, \dot{\mathbf{q}})+\mathbf{G}(\mathbf{q})
\end{gathered}
$$

where $\mathbf{J}_{\mathbf{m}}, \mathbf{B}_{\mathbf{m}}$ and $\mathbf{K}_{\mathbf{m}}$ are the $n \times n$ diagonal matrices of the motor and transmission inertias, damping and stiffness, respectively. In the simulations we adopt $K_{\mathrm{m} i}=210^{6} \mathrm{Nm} \mathrm{rad}^{-1}$ and $\boldsymbol{B}_{\mathrm{m} i}=10^{4} \mathrm{Nms} \mathrm{rad}^{-1}(i=1,2)$.

The time response characteristics (Tables 3 and 4), namely the percent overshoot $P O \%$, the steady-state error $e_{\mathrm{ss}}$, the peak time $T_{\mathrm{p}}$ and the settling time $T_{\mathrm{s}}$ reveal that, if we consider similar performances for robots with ideal transmissions at the joints, the $F O$ is superior to 
the $P D-P I$ algorithms at the cases of robots with joint dynamic phenomena. I conclusion the $F O$ have good dynamic response for position and force perturbations.

\begin{tabular}{llllll}
\hline $\boldsymbol{N}_{\boldsymbol{o}}$ & $\boldsymbol{C}(\boldsymbol{s})$ & $\mathbf{P O} \%$ & $\boldsymbol{e}_{s s}[\mathrm{~mm}]$ & $\boldsymbol{T}_{\boldsymbol{p}}[\boldsymbol{s}]$ & $\boldsymbol{T}_{\boldsymbol{s}}[\boldsymbol{s}]$ \\
& $P D-P I$ & 43.0 & $5.010^{-3}$ & $2.110^{-2}$ & $15.010^{-2}$ \\
& $F O$ & 39.0 & $0.910^{-3}$ & $3.610^{-2}$ & $15.010^{-2}$ \\
& $P D-P I$ & 0.2 & $2.710^{-3}$ & $12.210^{-2}$ & $12.010^{-2}$ \\
& $F O$ & 0.3 & $3.510^{-3}$ & $10.010^{-2}$ & $10.010^{-2}$ \\
\multirow{3}{*}{3} & $P D-P I$ & 0.3 & $64.010^{-2}$ & $16.010^{-2}$ & $16.010^{-2}$ \\
& $F O$ & 0.3 & $5010^{-3}$ & $8.010^{-2}$ & $8.010^{-2}$ \\
\hline
\end{tabular}

Table 3. Time response characteristics for a pulse $\delta y_{d}$ at the robot A position reference.

\begin{tabular}{|c|c|c|c|c|c|}
\hline$N_{o}$ & $C(s)$ & $P O \%$ & $e_{s s}[m m]$ & $T_{p}[s]$ & $T_{s}[s]$ \\
\hline \multirow{2}{*}{1} & $P D-P I$ & 400.0 & $9.810^{-1}$ & $11.010^{-2}$ & $2.010^{-1}$ \\
\hline & $F O$ & 115.0 & $77.010^{-3}$ & $25.010^{-2}$ & $2.010^{-1}$ \\
\hline \multirow{2}{*}{2} & $P D-P I$ & 400.0 & $9.810^{-1}$ & $15.010^{-2}$ & $10.010^{-1}$ \\
\hline & $F O$ & 100.0 & $77.010^{-3}$ & $10.010^{-2}$ & $4.010^{-1}$ \\
\hline \multirow{2}{*}{3} & $P D-P I$ & 100.0 & $9.810^{-1}$ & $15.010^{-2}$ & $10.010^{-1}$ \\
\hline & FO & 100.0 & $77.010^{-3}$ & $10.010^{-2}$ & $4.010^{-1}$ \\
\hline
\end{tabular}

Table 4. Time response characteristics for a pulse $\delta \mathrm{F}_{\mathrm{d}}$ at the robot A force reference.
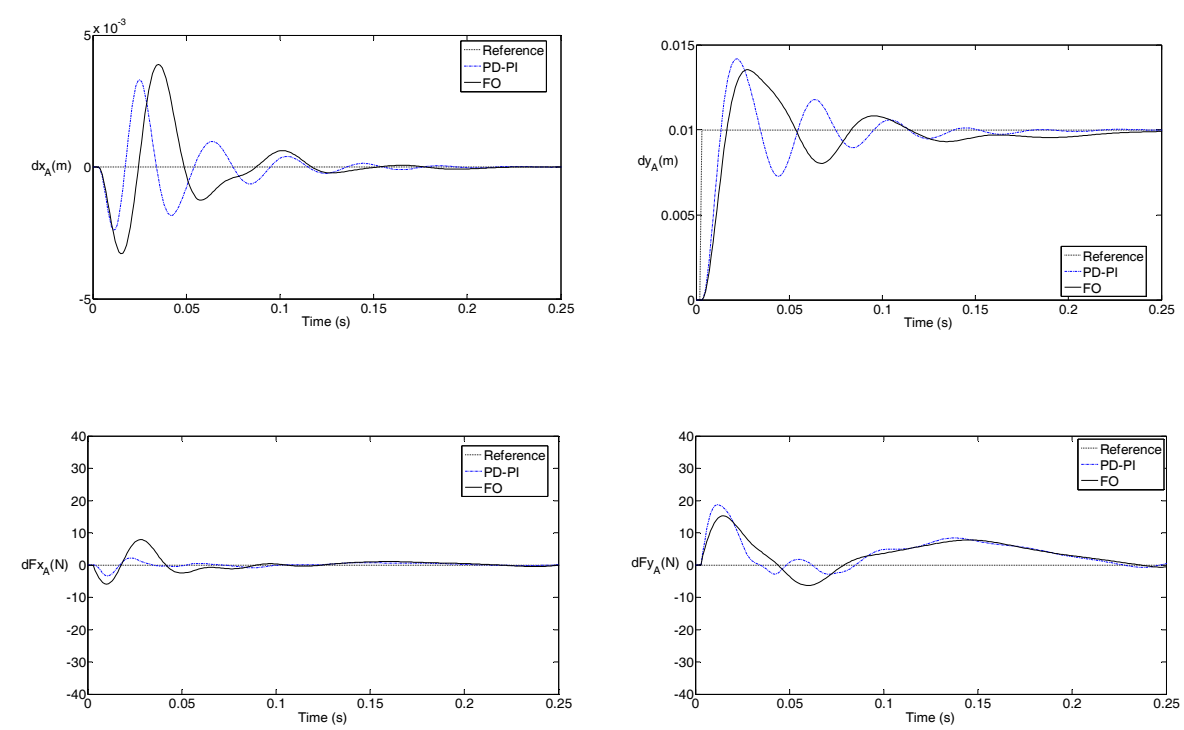

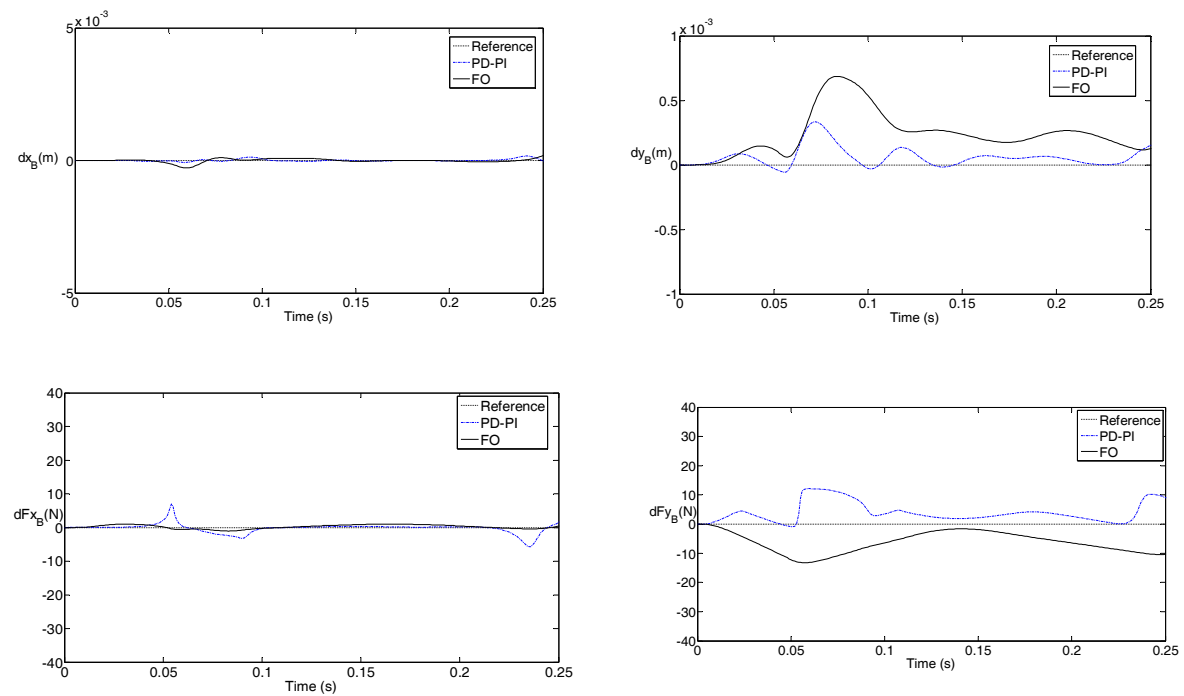

Fig. 4. Time response for robots $\mathrm{A}$ and $\mathrm{B}$ with ideal joints under the action of the $F O$ and the $P D-P I$ algorithms for a pulse perturbation at the robot A position reference $\delta y_{\mathrm{d}}=10^{-3} \mathrm{~m}$ and a payload with $M=1 \mathrm{~kg}, B_{\mathrm{i}}=10 \mathrm{Nsm}^{-1}$ and $K_{\mathrm{i}}=10^{3} \mathrm{Nm}^{-1}$.
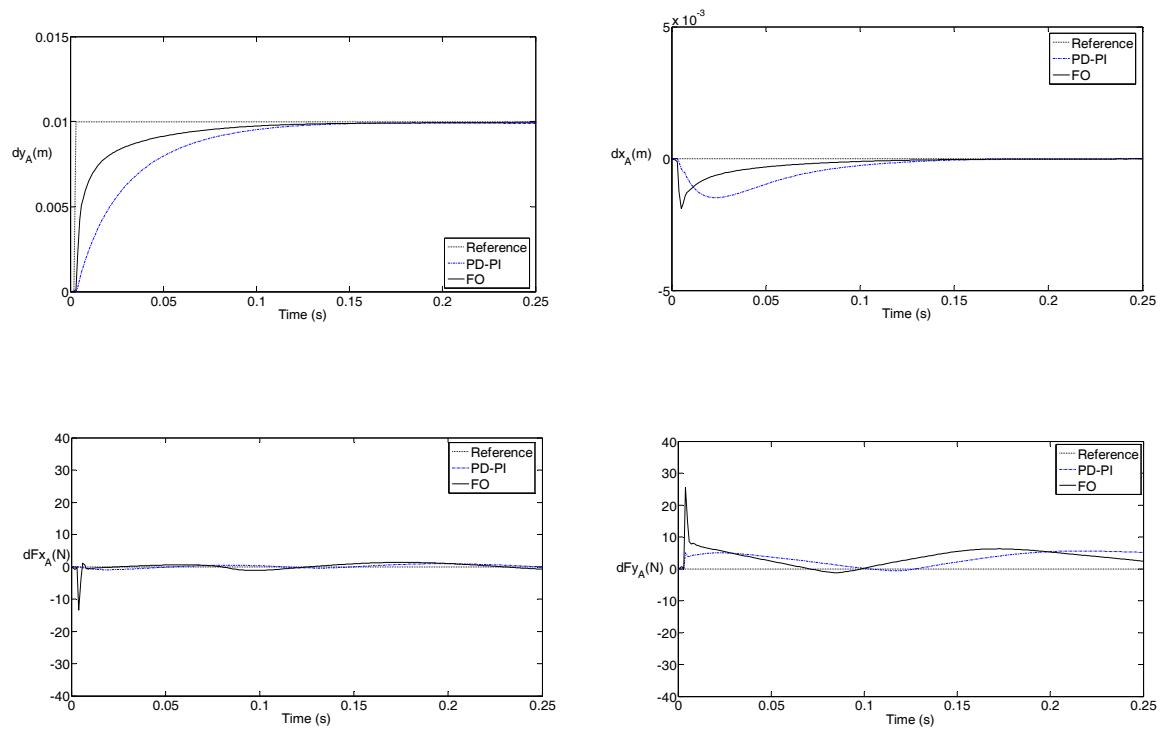

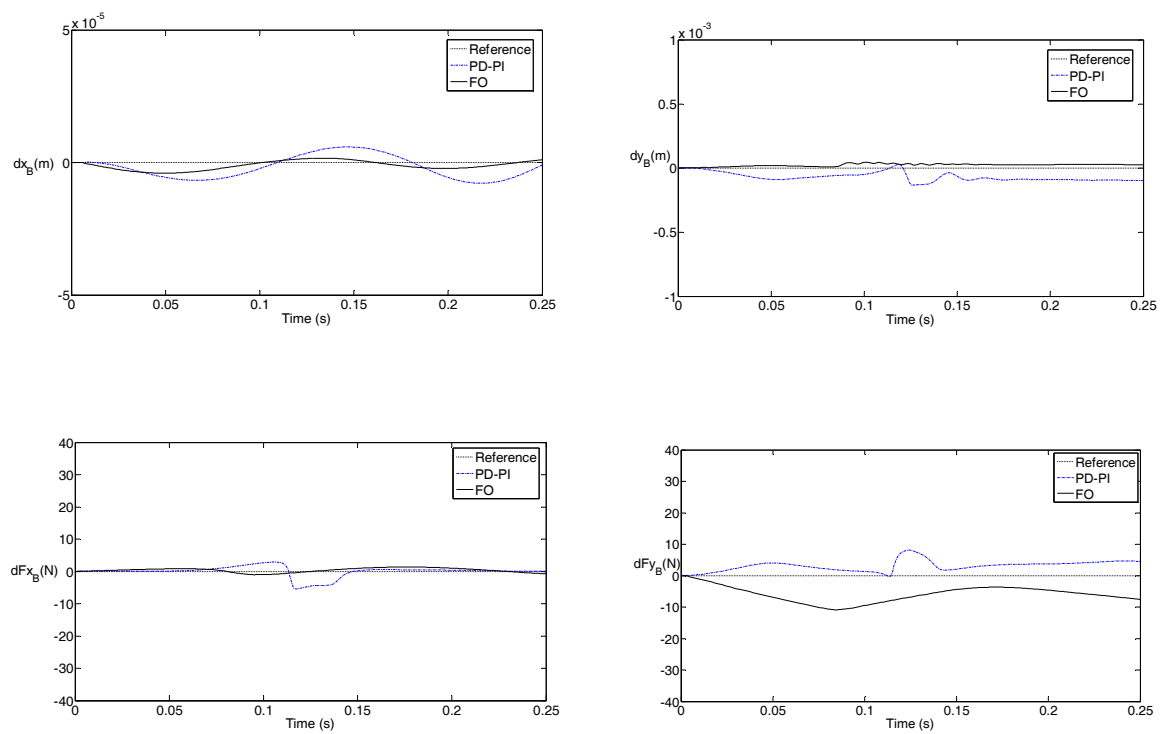

Fig. 5. Time response for robots $\mathrm{A}$ and $\mathrm{B}$ with joints having backlash under the action of the $F O$ and the $P D-P I$ algorithms for a pulse perturbation at the robot A position reference $\delta y_{\mathrm{d}}=$ $0.1 \mathrm{~m}$ and a payload with $M=1 \mathrm{~kg}, B_{\mathrm{i}}=10 \mathrm{Nsm}^{-1}$ and $K_{\mathrm{i}}=10^{3} \mathrm{Nm}^{-1}$.
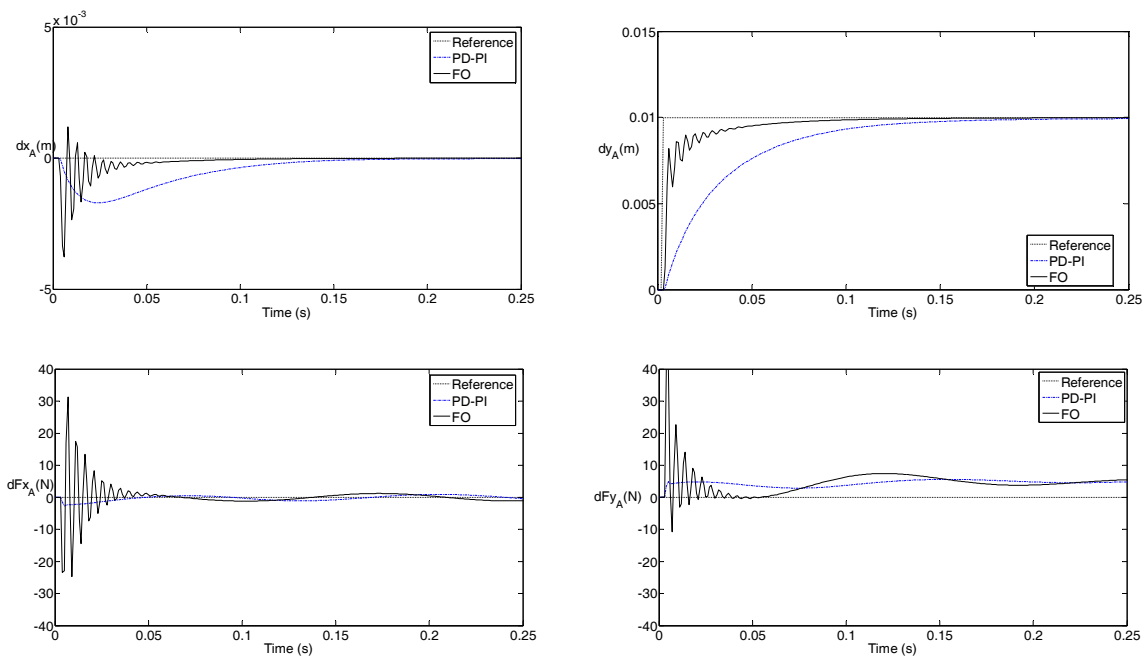

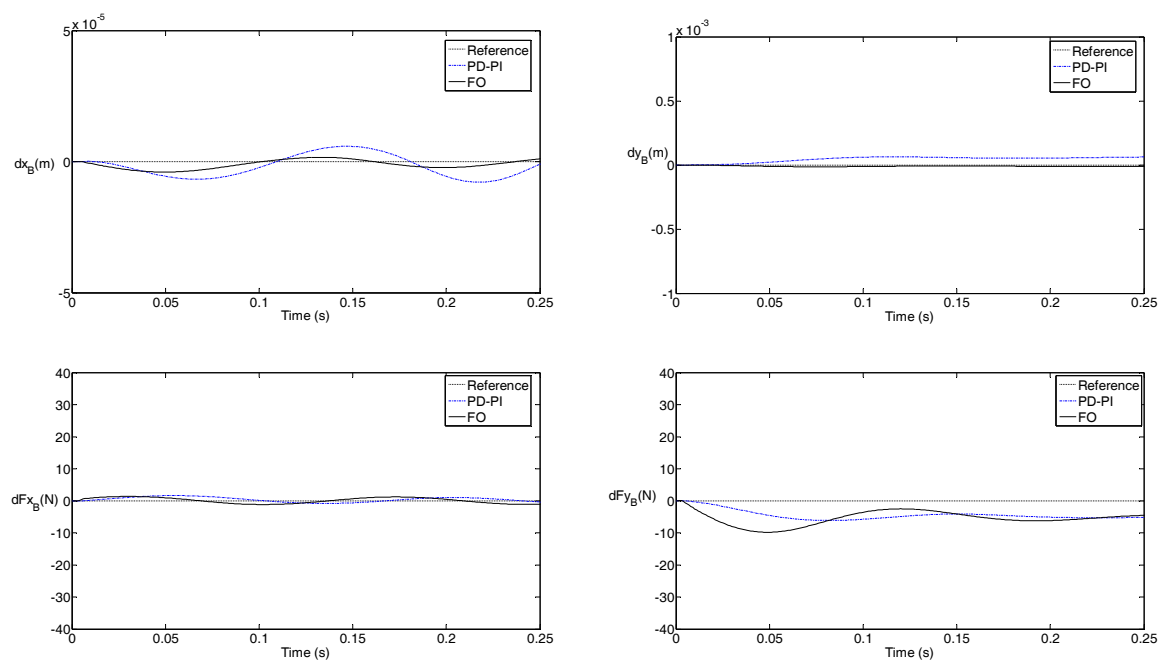

Fig. 6. Time response for robots $\mathrm{A}$ and $\mathrm{B}$ with joints having flexibility under the action of the $F O$ and the $P D-P I$ algorithms for a pulse perturbation at the robot A position reference $\delta y_{\mathrm{d}}=$ $0.1 \mathrm{~m}$ and a payload with $M=1 \mathrm{~kg}, B_{\mathrm{i}}=10 \mathrm{Nsm}^{-1}$ and $K_{\mathrm{i}}=10^{3} \mathrm{Nm}^{-1}$.

\section{Conclusion}

This paper studied the position/force control of two robots working in cooperation using fractional and integer order control algorithms. The system time response was analyzed for manipulators having several types of dynamical phenomena at the joints. The transient response of the system shows the superior performance of the FO controller.

\section{References}

Y. C. Tsai \& A.H Soni. (1981) "Accessible Region and Synthesis of Robot Arms". ASME Journal of Dynamic Systems, Measurement and Control. Vol. 103, pp. 803-811, 1981.

T. Yoshikawa, (1985) "Manipulability of Robotic Mechanisms". Int. J. Robotics Research. Vol. 4, pp. 3-9.

H. Asada, (1983) "A Geometrical Representation of Manipulator Dynamics and its Application to Arm Design". ASME Journal of Dynamic Systems, Measurement and Control. Vol. 5, pp. 131-142.

J. A. Tenreiro. Machado \& A. M. Galhano, (1997) “A Statistical and Harmonic Model for Robot Manipulators". In: Proc. of IEEE Int. Conf. on Robotics and Automation, Albuquerque, New Mexico, USA, pp. 231-242.

J. A. Tenreiro Machado, (1997) "Analysis and Design of Fractional-Order Digital Control Systems". Journal Systems Analysis, Modelling and Simulation. Vol. 27, No 1, pp. 107122. 
Y. Nakamura, K. Nagai, T. Yoshikawa, (1989) “Dynamics and Stability in Coordination of Multiple Robotic Mechanisms". International Journal of Robotics Research. Vol. 8, pp. 44-61.

T. J. Tarn, A. K. Bejczy, P. K., (1996) “Analysis of the Dynamic Ability of Two Robot Arms in Object Handling". Advanced Robotics. Vol. 10, No 10, pp. 301-315.

N. M. Fonseca Ferreira, J. A. Tenreiro Machado, (2000) “Manipulability Analysis of TwoArm Robotic Systems". In: Proc. of IEEE International Conference on Intelligent Engineering Systems. Vol. 1, No 1, pp. 101-109.

A. K. Bejczy and T. Jonhg Tarn, (2000) "Redundancy in Robotics Connected Robots Arms as Redundant Systems". In: Proc. of IEEE International Conference on Intelligent Engineering Systems, Vol. 1, No 1, pp. 310-319.

M. H. Raibert and J. J. Craig, (1981) "Hybrid Position/Force Control of Manipulators". ASME Journal of Dynamic Systems, Measurement and Control. Vol. 1, pp. 226-233.

N. Hogan, (1985) "Impedance control: An Approach to Manipulation, Parts I-Theory, IIImplementation, III- Applications". ASME J. of Dynamic Systems, Measurement and Control. Vol. 107, No 1 pp. 1-24,.

Kumar, Manish; Garg, Devendra P.(2005), "Neuro-fuzzy control applied to multiple cooperating robots", Industrial Robot: An International Journal, Volume 32, Number 3, pp. 234-239.

Ahin Yildirim, (2005) “A Proposed Hybrid Recurrent Neural Control System for Two Cooperating Robots", Journal of Intelligent and Robotic Systems, v.42 n.1, p.95-111.

Jufeng Peng, Srinivas Akella, (2005) “Coordinating Multiple Robots with Kinodynamic Constraints Along Specified Paths" The International Journal of Robotics Research Vol. 24, No. 4, pp. 295-310.

N. M. Fonseca Ferreira \& J. A. Tenreiro Machado, (2003) "Fractional-Order Hybrid Control of Robotic Manipulator". In: Proc. of 10th IEEE Int. Conf. on Advanced Robotics, Coimbra, Portugal. Vol. 1, No 1, pp. 221-229.

N. M. Fonseca Ferreira, J. A. Tenreiro Machado, J. Boaventura Cunha, “Fractional - Order Position/Force Robot Control". In: Proc. of 2nd IEEE Int. Conference on Computational Cybernetics, Vienna, Austria. Vol. 1, No 1, pp. 126-133, 2004.

N. M. Fonseca Ferreira \& J. A. Tenreiro Machado, (2005) “Fractional-Order Position/Force Robot Control". Journal of Advanced Computational Intelligence and Intelligent Informatics. Vol. 9, No 4, pp. 379-386. 


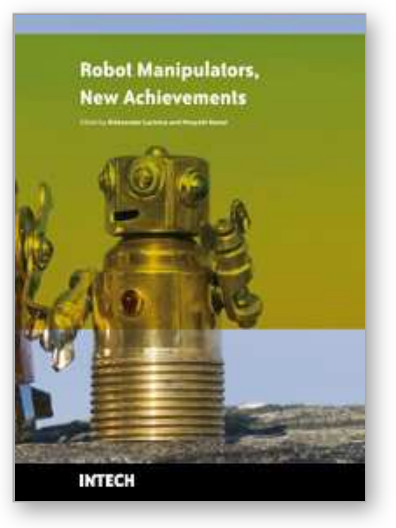

\author{
Robot Manipulators New Achievements \\ Edited by Aleksandar Lazinica and Hiroyuki Kawai
}

ISBN 978-953-307-090-2

Hard cover, 718 pages

Publisher InTech

Published online 01, April, 2010

Published in print edition April, 2010

Robot manipulators are developing more in the direction of industrial robots than of human workers. Recently, the applications of robot manipulators are spreading their focus, for example Da Vinci as a medical robot, ASIMO as a humanoid robot and so on. There are many research topics within the field of robot manipulators, e.g. motion planning, cooperation with a human, and fusion with external sensors like vision, haptic and force, etc. Moreover, these include both technical problems in the industry and theoretical problems in the academic fields. This book is a collection of papers presenting the latest research issues from around the world.

\title{
How to reference
}

In order to correctly reference this scholarly work, feel free to copy and paste the following:

N. M. Fonseca Ferreira, J. A. Tenreiro Machado and Jozsef K. Tar (2010). Two Cooperating Manipulators with Fractional Controllers, Robot Manipulators New Achievements, Aleksandar Lazinica and Hiroyuki Kawai (Ed.), ISBN: 978-953-307-090-2, InTech, Available from: http://www.intechopen.com/books/robot-manipulators-newachievements/two-cooperating-_manipulators-with-fractional-controllers

\section{INTECH}

open science | open minds

\section{InTech Europe}

University Campus STeP Ri

Slavka Krautzeka 83/A

51000 Rijeka, Croatia

Phone: +385 (51) 770447

Fax: +385 (51) 686166

www.intechopen.com

\section{InTech China}

Unit 405, Office Block, Hotel Equatorial Shanghai

No.65, Yan An Road (West), Shanghai, 200040, China

中国上海市延安西路65号上海国际贵都大饭店办公楼405单元

Phone: +86-21-62489820

Fax: +86-21-62489821 
(C) 2010 The Author(s). Licensee IntechOpen. This chapter is distributed under the terms of the Creative Commons Attribution-NonCommercialShareAlike-3.0 License, which permits use, distribution and reproduction for non-commercial purposes, provided the original is properly cited and derivative works building on this content are distributed under the same license. 